\title{
Neglected case of congenital hypothyroidism in a 17-year- old female
}

\author{
Mahmoud Medhat Mahmoud
}

\begin{abstract}
Introduction: Congenital hypothyroidism is one of the most common endocrinal disorders in newborns. The slow development of obvious clinical symptoms, coupled with the importance of early treatment led to the implementation of widespread newborn screening for this condition. Case Report: This paper presents a case of congenital hypothyroidism that was born at home and was not screened for hypothyroidism. A 17-year-old female patient complained of short stature, mental retardation, delayed puberty and chronic constipation as a result of neglected hypothyroidism. Conclusion: This case discusses the importance of neonatal screening programs for early detection of congenital hypothyroidism cases that are unfortunately still being neglected in some areas of developing countries. It also shows the value of early and adequate replacement therapy for the detected cases as this could protect them against irreversible growth retardation and mental retardation. This is because any diagnostic delay, inadequate treatment or even poor compliance to treatment is always associated with irreversible damage as those manifested in this case.
\end{abstract}

Keywords: Hypothyroidism, Short stature, Neonatal screening

Mahmoud Medhat Mahmoud

Affiliations: ${ }^{1}$ Alexandria Faculty of Medicine-Fifth Year Medical Student, Alexandria University, Alexandria, EGYPT

Corresponding Author: Mahmoud Medhat Mahmoud, 89 Ebn Monkez St. behind Al Horreya Police Station, Victoria, Alexandria, EGYPT- 21611; EGY +2 0100-356-7957; Email: mahmoud.medhat@hotmail.com

Received: 18 January 2013

Accepted: 11 June 2013

Published: 01 September 2013
Mahmoud MM. Neglected case of congenital hypothyroidism in a 17-year-old female. International Journal of Case Reports and Images 2013;4(9):481-484.

$* * * * * * * * *$

doi:10.5348/ijcri-2013-09-361-CR-5

\section{INTRODUCTION}

Congenital hypothyroidism is defined as thyroid hormone deficiency present at birth. Problems with thyroid gland development (dysgenesis) and disorders of thyroid hormone biosynthesis (dyshormonogenesis) are the most common causes of congenital hypothyroidism.

Newborn screening for hypothyroidism is not done in many third world countries. Only an estimated onethird of the worldwide birth population is screened. It is, therefore, important that clinicians could be able to recognize and treat the disorder [1]. Also health education with early signs and symptoms of the condition is very important especially in areas where neonatal screening against hypothyroidism is not performed.

This case report describes a neglected case of hypothyroidism that was left untreated for 17 years. The reasons behind this negligence are mainly that the patient was not screened against hypothyroidism at birth. In addition, her parents were not aware of the signs of the condition.

\section{CASE REPORT}

A 17-year-old patient was brought by her mother to Alexandria University Hospital, complaining of delayed puberty, short stature, mental retardation and chronic constipation. She was born at home to a family of low socio-economic conditions and was not screened for hypothyroidism at birth. She reported that the patient 
was hypoactive and not interested in the surroundings since early childhood, but the case was neglected and the mother never asked for medical advice before.

Upon physical examination the patient was obese. She had very short stature with a height of $129 \mathrm{~cm}(<3$ rd percentile). She had large head, short neck, coarse facial features with myxedematous appearance, macroglossia and depressed nasal bridge (Figure 1). Her skin was cold and dry. The patient's vital signs were normal.

Abdominal examination revealed generalized abdominal distention (pot belly) with umbilical hernia, otherwise abdominal ultrasound revealed normal abdomen. Neurological examination showed generalized hypotonia and hyporeflexia with positive Woltman sign (delayed relaxation phase of elicited deep tendon reflexes). The patient was mentally retarded and had low IQ level. The computed tomography (CT) scan of brain was normal. Pulmonary and cardiac examinations were within normal limits.

Laboratory examination showed high TSH levels. TSH measured $536 \mathrm{IU} / \mathrm{mL}$, with low levels of free $\mathrm{T} 4$ and $\mathrm{T}_{3}$ (T4 was $32 \mathrm{ng} / \mathrm{mL}$, T3 was $0.6 \mathrm{ng} / \mathrm{mL}$ ). Accordingly, diagnosis of primary hypothyroidism was established and replacement therapy with levothyroxine was started to normalize the levels of TSH. Chronic constipation was treated with laxatives.

After two years of treatment, the condition improved slightly where the patient became more oriented and interested in the surroundings, constipation was treated and artificial menstruation was induced at the age of 19 years.

\section{DISCUSSION}

The incidence of congenital hypothyroidism based on neonatal laboratory screening is greater than the incidence based on clinical signs and symptoms. The incidence of the condition depending on clinical diagnosis has been found to vary between 1:5800 and 1:6900, whereas based on neonatal screening the incidence is between 1:2900 and 1:3600. This discrepancy may be due to the fact that some children with the disorder go undetected when general laboratory screening is not utilized. On the other hand, neonatal laboratory screening will detect some children with minor disturbance of thyroid function which are clinically insignificant [2].

Thyroid hormones are important for normal growth hormone and IGF functions. Hypothyroidism is associated with a reduction in the pulsatile growth hormone secretion and in growth hormone response to stimulatory tests. In hypothyroidism, serum levels of IGF-I and IGFBP-3 fall dramatically. In a study of 12 patients with hypothyroidism, it was found that long-term replacement therapy in children with hypothyroidism is associated with a physiological increase in IGF-1 and IGFBP-3 [3]. However, studies have also concluded that catch-up growth in hypothyroidism may be

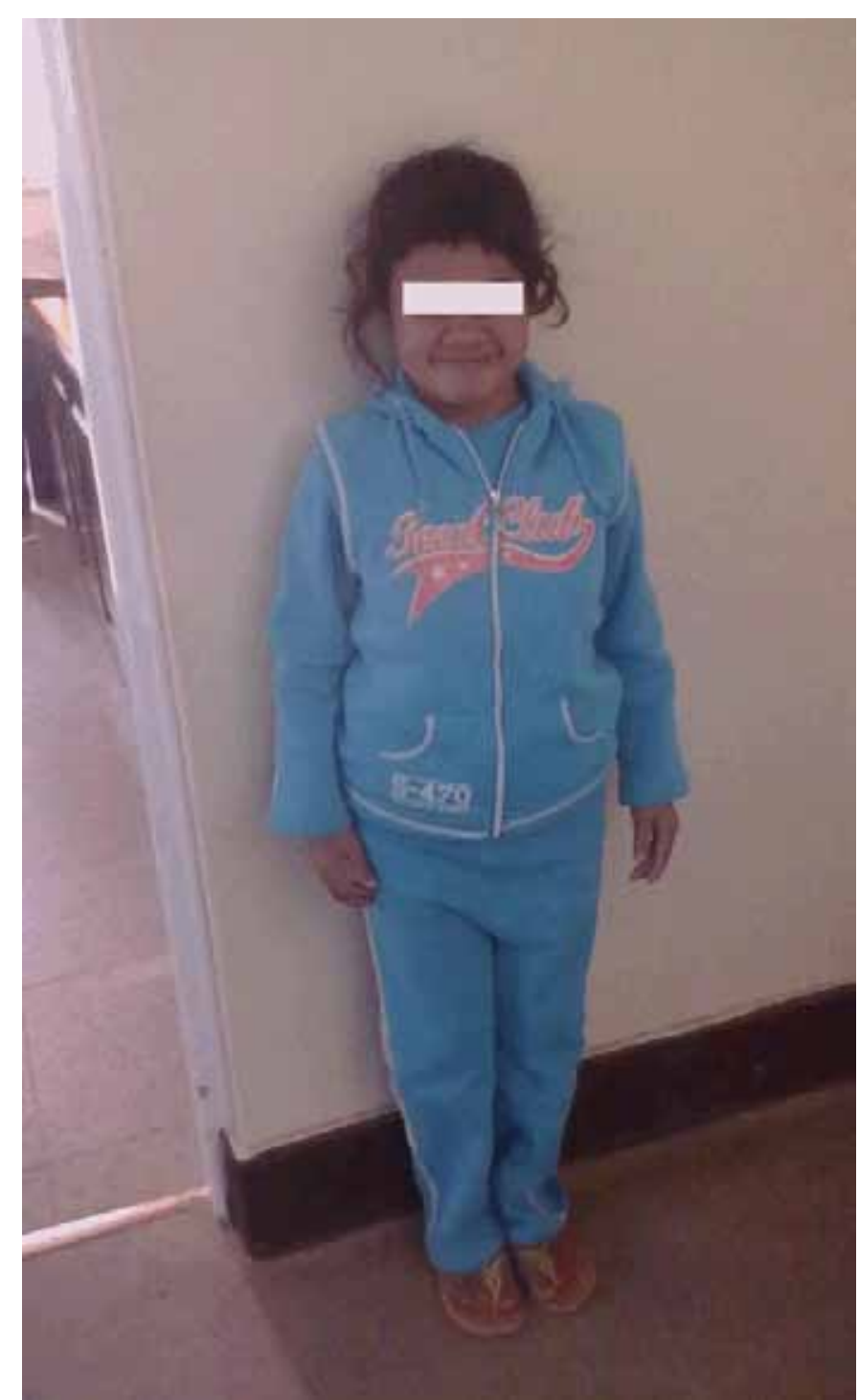

Figure 1: Short stature (height: $129 \mathrm{~cm}$ ) and myxedematous appearance in a 17-year-old female patient with neglected congenital hypothyroidism.

incomplete if treatment has been started shortly before or during puberty [4]. So despite treatment, prolonged hypothyroidism may result in compromised adult height in some patients. The contributing factors to this height deficit may include the duration of hypothyroidism, the height deficit at the time of the diagnosis, etiological differences and the diminished potential for catch-up growth in late-diagnosed hypothyroidism [5].

A follow-up study of 30 patients with congenital hypothyroidism concluded that early detection by neonatal screening and treatment enables normal prepubertal and pubertal growth and the achievement of normal adult height, following normal puberty. Adult height in congenital hypothyroidism is significantly correlated with parental height and the mean L-T4 daily dose administered over the first six months of treatment [6]. 
Another complication of neglected or inadequately treated hypothyroidism is mental retardation. Normal brain development depends on delivery of adequate thyroid hormone for the first 2-3 years of life. Low thyroid levels during this time may result in irreversible damage, whereas hypothyroidism developed after the age of 3 years, it leads to reversible effects if it is early and adequately treated [1].

The New England Congenital Hypothyroidism Collaborative reported that a subgroup of 18 infants who had low serum $\mathrm{T}_{4}$ levels (average $\mathrm{T}_{4} 8.6 \mu \mathrm{g} / \mathrm{dL}$ ) and low l-thyroxine dosing ( $<5 \mu \mathrm{g} / \mathrm{kg} /$ day) with a history of poor compliance in the first three years of life, had a mean IQ of 87. The larger, adequately treated group, with a serum $\mathrm{T}_{4}$ in the target range (average $\mathrm{T}_{4} 11.2 \mu \mathrm{g} / \mathrm{dL}$ ), had an IQ score of 105. This study concluded that $\mathrm{T} 4$ values in the lower part of the normal range are probably incompatible with maximal intellectual development and every effort should be exerted to maintain serum $\mathrm{T} 4$ levels in the upper half of the normal range during the first year of life [7].

It was found that diagnostic delay of hypothyroidism was associated with a steady decline in mean IQ (Wechsler intelligence scale) in a retrospective study of 141 hypothyroid children where the mean IQ was 79.5 for children with congenital hypothyroidism, but was normal in children diagnosed before the age of 6 weeks [8]. And many other studies concluded that IQ levels of early treated congenital hypothyroidism patients detected by neonatal screening programs can be within normal range and they can have normal school attainments [9].

\section{CONCLUSION}

In conclusion, growth retardation and mental retardation of children due to hypothyroidism can be totally prevented by three things. First to follow a strict neonatal screening program for hypothyroidism that is unfortunately still being neglected in some areas of the developing countries. Therefore, health education to parents in these countries about the main signs and symptoms of hypothyroidism is very important. Second is the adequate and very early L-thyroxin replacement therapy. Third is very careful follow-up of patients and adjustment of the L-thyroxin dose to maintain serum $\mathrm{T} 4$ levels in the upper half of the normal range during the first year of life. This is because any diagnostic delay, inadequate treatment or even poor compliance to treatment is always associated with irreversible damage as those manifested in this case.

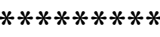

\section{Author Contributions}

Mahmoud Medhat Mahmoud - Conception and design, Acquisition of data, Analysis and interpretation of data,
Drafting the article, Critical revision of the article, Final approval of the version to be published

\section{Guarantor}

The corresponding author is the guarantor of submission.

\section{Conflict of Interest}

Authors declare no conflict of interest.

\section{Copyright}

(C) Mahmoud Medhat Mahmoud et al. 2013; This article is distributed under the terms of Creative Commons attribution 3.0 License which permits unrestricted use, distribution and reproduction in any means provided the original authors and original publisher are properly credited. (Please see www.ijcasereportsandimages.com/ copyright-policy.php for more information.)

\section{REFERENCES}

1. Maynika V Rastogi, Stephen H LaFranchi. Congenital hypothyroidism. Orphanet J Rare Dis 2010;5:17.

2. Alm J, Hagenfeldt L, Larsson A, Lundberg K. Incidence of congenital hypothyroidism: Retrospective study of neonatal laboratory screening versus clinical symptoms as indicators leading to diagnosis. Br Med J (Clin Res Ed) 1984 Nov 3;289(6453):1171-5.

3. Bona G, Rapa A, Boccardo G, Silvestro L, Chiorboli E. IGF-1 and IGFBP-3 in congenital and acquired hypothyroidism after long-term replacement treatment. Panminerva Med 1998 Jun;40(2):103-6.

4. Boersma B, Otten BJ, Stoelinga GB, Wit JM. Catch-up growth after prolonged hypothyroidism. Eur J Pediatr 1996 May;155(5):362-7.

5. Kandemir N, Yordam N. Height prognosis in children with late-diagnosed congenital hypothyroidism. Turk J Pediatr 2001 Oct-Dec;43(4):303-6.

6. Dickerman Z, De Vries L. Prepubertal and pubertal growth, timing and duration of puberty and attained adult height in patients with congenital hypothyroidism $(\mathrm{CH})$ detected by the neonatal screening programme for $\mathrm{CH}--\mathrm{a}$ longitudinal study. Clin Endocrinol (Oxf) 1997 Dec;47(6):649-54.

7. Characteristics of infantile hypothyroidism discovered on neonatal screening. J Pediatr 1984 Apr;104(4):539-44.

8. Hulse JA. Outcome for congenital hypothyroidism. Arch Dis Child 1984 Jan;59(1):23-9.

9. Bargagna S, Dinetti D, Pinchera A, et al. School attainments in children with congenital hypothyroidism detected by neonatal screening and treated early in life. Eur J Endocrinol 1999 May;140(5):407-13. 
Access PDF of article on other devices other devices

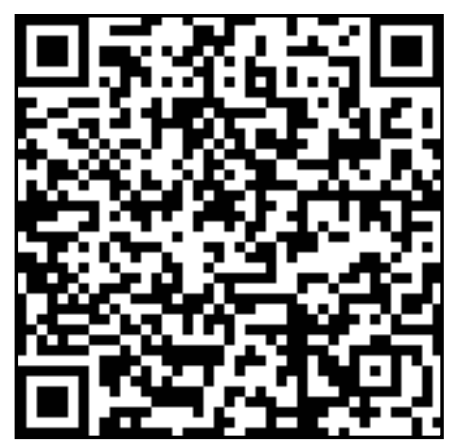

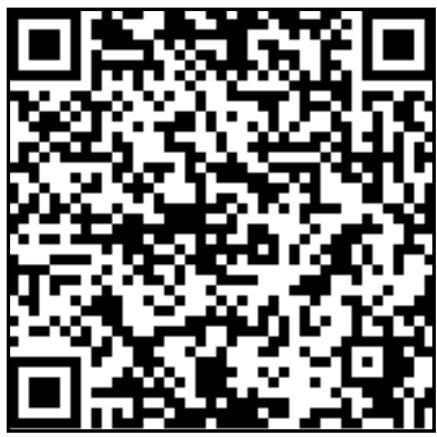

